\title{
TINJAUAN KESATUAN DARI KEPELBAGAIAN MENURUT KITAB-KITAB INJIL DAN SURAT-SURAT PAULUS
}

Waharman

waharman@sttab.ac.id

\begin{abstract}
The purpose of this writing is so that church officials and all church members truly realize that they are members of the body of Christ. Just as the limbs seem less important but are given special respect, they are not needed by beautiful members. Based on the analogy of the church as the body of Christ, the church division is something that is very absurd, something that does not make sense to happen. Where there are limbs that conflict with one another. It is very insane for members to hurt one another. But historical reality has not counted how many conflicts have caused disunity. Believers have failed to analogize themselves with the Body of Christ. The Church is not an earthly organization or social institution. The church is the body of Christ and should not be treated as a social organization. The church is beyond any organization because there is life in it. A deep awareness of the church as the body of Christ will lead to responsibility, humility to cooperate, avoiding the danger of division which often threatens the integrity of the church.
\end{abstract}

Keywords: Unity, diversity, gospel, Paul's Letters.

Abstrak: Tujuan penulisan ini adalah supaya pejabat gereja dan seluruh warga gereja sungguh-sungguh menyadari bahwa dirinya adalah anggota tubuh Kristus. Sama seperti anggota tubuh yang nampaknya kurang penting tetapi diberikan penghormatan khusus, hal itu tidak diperlukan oleh anggota yang elok. Berdasarkan analogi gereja sebagai tubuh Krisus, maka perpecahan gereja adalah sesuatu yang sangat absurd, sesuatu yang sangat tidak masuk akal untuk terjadi perpecahan. Mana ada anggota tubuh yang bertentangan satu dengan yang lain. Adalah sangat tidak waras apabila anggota tubuh saling menyakiti satu dengan yang lain. Tetapi kenyataan sejarah sudah tidak terhitung berapa banyak terjadinya konflik yang menyebabkan terjadinya perpecahan. Orang percaya telah gagal untuk menganalogikan dirinya dengan Tubuh Kristus.Gereja bukanlah sebuah organisasi duniawi atau sebuah lembaga social. Gereja adalah tubuh Kristus dan tidak boleh diperlakukan sebagai organisasi social. Gereja melebihi organisasi apapun juga karena di dalamnya ada kehidupan. Kesadaran yang mendalam akan gereja sebagai tubuh Kristus akan menimbulkan tanggung jawab, kerendahan hati untuk bekerjasama, menghindarkan bahaya perpecahan yang seringkali mengancam keutuhan gereja.

Kata Kunci: Kesatuan, kepelbagaian, Injil, Surat-surat Paulus.

\section{LATAR BELAKANG}

Sepanjang sejarah gereja, mulai zaman para rasul sampai pada awal abad dua puluh satu ini, gereja dan lembaga-lembaga rohani seperti yayasan-yayasan Kristen terus berhadapan dengan ancaman perpecahan. Perpecahan dalam gereja telah membawa dampak yang negatif secara internal (Persekutuan sesama orang percaya): timbulnya 
permusuhan, kebencian, dendam, kepahitan bahkan pembunuhan. Dampak secara negatif secara internal ini mengakibatkan dampak yang negatif pula secara eksternal yaitu menyangkut kesaksian orang yang percaya kepada dunia ini, gereja kehilangan fungsinya sebagai garam dan terang. Gereja kehilangan fungsi untuk mempengaruhi dan membimbing orang lain untuk percaya kepada Kristus dan hidup dalam kebenaran. Meskipun dunia ini tercabik-cabik oleh permusuhan dan perpecahan tetapi dunia ini mencibir tatkala melihat gereja terpecah dan hidup dalam permusuhan. Sebuah pernyataan yang membuat orang Kristen seharusnya menjadi malu, sedih dan bertobat tatkala seorang yang sangat cinta damai, yaitu Mahatma Gandhi (1869-1948) mengatakan: "Saya mencintai Kristus kalian, tetapi tidak agama kalian”.

Berdasarkan analisa masalah yang dihadapi oleh gereja tersebut di atas, maka: tidak boleh terjadi perpecahan dalam gereja, karena gereja adalah tubuh Kristus dengan kepelbagaian anggota. Satu kesatuan dengan banyak anggota (1Korintus 12-14). Perpecahan gereja itu telah mengakibatkan tumbuhnya akar pahit dan dendam sejarah. Bahkan tidak sedikit akar pahit dan dendam sejarah ini diwariskan sampai kepada anak cucu. Pada bagian ini, "kepelbagaian dalam kesatuan" akan dibahas dari sudut pandang ke empat Injil, Kisah Para rasul, Surat-surat rasul Paulus. Dari pembahasan ini diharapkan dapat ditemukan aspek-aspek yang berhubungan Kesatuan dari Kepelbagaian, kegagalan dalam mempertahankan persatuan dari kepelbagaian, serta faktor-faktor penunjang sehingga persatuan semakin kuat dan mencapai tujuannya.

\section{Kesatuan Dari Kepelbagaian Dalam Kitab-Kitab Injil}

Allah Tritunggal adalah sumber kepelbagaian dalam gereja. Baik menyangkut kepelbagaian karunia, kepelbagaian anggota (1 Korintua 12) dan kepelbagaian jabatan (Efesus 4:11-12). Demikian juga dalam Kisah 20:28 mengungkapkan bahwa jemaat diperoleh melalui darah Yesus Kristus. Dengan demikian gereja yang adalah Tubuh Kristus yang terdiri dari anggota-anggota gereja maupun pejabat-pejabat gereja, adalah berasal dari Allah. Demikian juga ungkapan: ”... di atas Batu karang ini Aku akan

\footnotetext{
${ }^{1}$ Kepelbagaian (diversity), memiliki pengertian: "banyak, bermacam-macam, menunjuk kepada halhal yang dapat dihitung (Quantitas).Dalam hal ini menunjuk kepada banyaknya anggota, dengan kepelbagaian karunia, karakter, latar belakang etnis, strata social, pejabat gereja dll. Kesatuan (unity) memiliki pengertian: "keesaan, sifat tunggal. Sedangkan persatuan berarti: "gabungan ( ikatan, kumpulan dsb) ${ }^{1}$ Maka "Kesatuan dari Kpelbagaian" memiliki pengertian: hal-hal yang banyak itu, meskipun banyak adalah satu kesatuan, satu gabungan, tidak terpisah-pisahkan.
} 
mendirikan jemaatKu dan alam maut tidak akan menguasainya" (Matius 16:18) menunjukkan bahwa gereja sebagai tubuh Kristus, berasal dan dibangun oleh Allah.

Maksud Tuhan Yesus mendirikan jemaatNya adalah agar terjadi persekutuan (Koinonia), di antara sesama anggota tubuh, melayani satu dengan yang lain dalam kasih (Diakonia), yang membawa dampak bagi kesaksian gereja (Marturia) menjadi semakin efektif. Tuhan Yesus mengatakan bahwa ciri khas murid-muridNya adalah saling mengasihi. "Sama seperti Aku telah mengasihi kamu, demikian pula kamu harus saling mengasihi. Dengan demikian semua orang akan tahu, bahwa kamu adalah murid-muridKu, yaitu jikalau kamu saling mengasihi (Yohanes 13:34-35). Kesaksian Kristen akan semakin pudar tatkala dunia menyaksikan bahwa orang Kristen tidak memiliki lagi kasih satu dengan yang lain, bahkan dunia akan mencemooh tatkala terjadi pertikaian dan perpecahan dalam tubuh Kristus. Walaupun kisah Kekristenan seringkali dirusak oleh keegoisan dan ketamakan, perhatian kepada mereka yang lemah, sakit dan miskin selalu menjadi tanda orang Kristen sejati. Gereja perdana sungguh-sungguh termasyur karena karya-karyanya dalam hal kemurahan hati. Salah seorang dari musuh-musuh gereja perdana, Kaisar Yulianus si Murtad (kira-kira thn 361-363), mengeluh bahwa sulit baginya untuk memulihkan penyembahan berhala jika orang Kristen "memperhatikan mereka yang lemah, bukan hanya mereka yang beragama Kristen, melainkan juga mereka yang masih menyembah berhala". ${ }^{2}$ Dengan demikian perbuatan cinta kasih memperkuat kesaksian Kristen.

Amanat agung Pemberitaan injil diberikan kepada semua individu orang percaya, tetapi dilaksanakan dengan efektif oleh gereja sebagi tubuh Kristus secara kolektif (Mat 28:19-20, Mark 16:15, Luk 24:18-19, Kisah 1:8). Seseorang menjadi percaya oleh karena pemilihan kasih karunia Allah serta peran aktif gereja sebagai tubuh Kristus dalam melaksanakan tugasnya: Ada yang memberitakan Injil secara persuasif, ada yang mendoakan pemberitaan Injil tersebut, ada pula yang mensuport dana, serta adanya orang Kristen yang terus menujukkan kemurahan hati dan masih banyak karunia-karunia pendukung lainnya. Sehingga tidak boleh ada seorangpun yang mengklaim bahwa seseorang menjadi percaya hanya karena ada orang yang punya karunia perkhabaran Injil yang memberitakan injil kepada orang tersebut. Dengan demikian amanat Agung adalah

\footnotetext{
${ }^{2}$ Michael Collins \& Matthew A. Price, The Story Of Christianity (Penerbit Kanisius, 2006) 11
} 
amanat kepada gereja sebagai tubuh Kristus. Semua elemen harus berfungsi sesuai dengan karunia yang diberikan kepadanya, sehingga kesaksian Kristen menjadi efektif.

Doa Tuhan Yesus dalam Yohanes 17:20-21 adalah doa bagi kesatuan muridmurid (Koinonia) bagi sebuah efektifitas kesaksian (Marturia): "Dan bukan untuk mereka ini saja aku berdoa, tetapi juga untuk orang-orang yang percaya kepadaKU oleh pemberitaan mereka, supaya mereka semua menjadi satu, sama seperti Engkau ya Bapa, di dalam Aku dan Aku di dalam Engkau agar mereka juga di dalam Kita, supaya dunia percaya bahwa Engakaulah yang mengutus Aku". Maka apabila tubuh Kristus tidak bersatu, ia tidak hidup sebagaimana Allah Tritunggal hidup, ia mengingkari hakekat gereja sebagai tubuh Kristus dan menjadi batu sandungan sehingga orang tidak percaya kepada Tuhan Yesus Kristus.

Keempat Injil tidak membahas secara khusus tentang kepelbagaian dalam kesatuan. Namun kehidupan Tuhan Yesus, apa yang Ia lakukan dan ajarkan berbicara tentang kepelbagaian dalam kesatuan. Para pengikut Tuhan Yesus dan para murid yang dipilihNya telah menunjukkan kepelbagaian. Kepelbagaian Latar belakang, ada yang berasal dari nelayan, pemungut cukai dan yang berlatar belakang aliran politik yang keras seperti Simon orang zelot.

Demikian juga amanat agung penginjilan yang diberikan kepada muridmuridNya akan membawa konsekwensi lahirnya gereja, sebagai tubuh Kristus yang terdiri dari berbagai suku bangsa. "....Karena itu pergilah, jadikanlah semua bangsa muridKu..." Mat 28:19-20. Dan kelak hasil penginjilan ini akan menjadi penghuni Sorga dan akan terdiri dari berbagai suku bangsa. "Aku berkata kepadamu: Banyak orang akan datang dari Timur dan Barat dan duduk makan bersama-sama dengan Abraham, Ishak dan Yakub di dalam Kerajaan Sorga" Mat 8:11. dan secara lebih jelas Wahyu 7:9 berbunyi: "Kemudian dari pada itu Aku melihat: Sesungguhnya, suatu kumpulan besar orang banyak yang tidak dapat terhitung banyaknya, dari segala bangsa dan suku dan kaum dan bahasa, berdiri di hadapan tahta dan di hadapan Anak Domba, memakai jubah putih dan memegang daundaun palem di tangan mereka.

Dengan demikian gereja sebagai tubuh Kristus tidak hanya diartikan sebagai jemaat lokal (Gereja yang kelihatan) tetapi juga menyangkut gereja yang Am, bersifat universal, yang tidak terikat oleh tempat dan melintasi waktu, melampaui denominasi dan organisasi (Gereja yang tidak kelihatan). Pemahaman gereja gereja sebagai tubuh Kristus 
yang bersifat universal berakar dari pemahaman gereja sebagai persekutuan umat Allah. "Tetapi kamulah bangsa yang terpilih, imamat yang rajani, bangsa yang kudus, umat kepunyaan Allah sendiri...1 Pet 2:9. Howard A. Snyder mengungkapkan hal ini sebagai berikut:

Kata Yunani untuk "umat" adalah "Laos" yang diterjemahkan ke dalam bahasa Inggris dengan kata "Laity" yang di Indonesiakan kembali menjadi "kaum awam". Hal ini mengingatkan kita bahwa seluruh gereja adalah umat atau laity atau awam. Hal ini untuk menekankan universalitas gereja. ${ }^{3}$

Doa yang Tuhan Yesus naikkan kepada Bapa di Sorga adalah doa yang tidak dibatasi oleh waktu dan tempat. Ia berdoa bagi murid-muridNya tetapi juga bagi semua orang yang percaya karena pemberitaan murid-muridNya. Dengan demikian doa Tuhan Yesus adalah doa untuk orang percaya segala zaman. DoaNya adalah supaya mereka semua menjadi satu (Yoh 17:20-21). Namun demikian kesatuan ini tidak hanya menyangkut gereja yang Am, gereja yang universal yang tidak dibatasi oleh waktu dan tempat (Invisible Church), tetapi juga menyangkut gereja yang kelihatan, gereja lokal, gereja yang terikat dalam satu wadah organisasi dan denominasi (Visible Church). Penekanan doa Tuhan Yesus ini adalah pada keperluan kasih yang matang, yang akan mempersatukan mereka bersama dalam menjalankan tugas bersama mereka. Meskipun mereka memiliki latar belkang yang berbeda dan intres yang berbeda, namun doa Tuhan Yesus tetaplah supaya mereka menjadi satu. Standard kesatuan itu bukanlah institusi atau lembaga, tetapi kesatuan Allah Tritunggal. "Sama seperti Engkau ya Bapa, di dalam Aku dan Aku di dalam Egkau, ....supaya mereka menjadi satu sama seperti Kita adalah satu. (Yoh 17:20-21). Tuhan Yesus berdoa sebagaimana Ia dan Bapa adalah pribadi yang berbeda namun satu, demikian Doa Tuhan Yesus menyangkut hubungan orang percaya satu dengan yang lain. Orang yang percaya, oleh kelahiran baru, masuk menjadi keluarga Allah, menjadi satu generasi yang rohani (Yoh 1:12-13) yang memiliki hubungan satu dengan yang lain seperti hubungan Bapa dan Anak. Itulah Doa Tuhan Yesus. Betapa hebat dan kuatnya persatuan yang Tuhan Yesus doakan.

Meskipun surat-surat Paulus banyak berbicara tentang pejabat-pejabat gereja seperti: Penatua, Diaken, gembala, Penginjil dll, namun perjanjian baru dan tulisan bapabapa gereja yang pertamalebih menekankan bahwa gereja bukanlah terutama institusi, melainkan persekutuan yang lebih bersifat kharismatis dan organis. Adanya penetapan

${ }^{3}$ Howard A. Snyder, The Community of the King, (Illinois: Inter Varsity Press, 1984) 58 
pejabat-pejabat gereja tersebut lebih menunjuk kepada fungsi sesuai dengan karunia yang dianugrahkan kepada masing-masing anggota. Gereja Baratlah yang pertama-tama lebih mengedepankan gereja sebagai institusi, sehingga lambat laun pengertian yang sebenarnya menjadi kabur. Hal ini sebagaimana dikutip oleh Snyder dari Hans Kung:

Perjanjian Baru dan tulisan Bapak-bapak gereja mula-mula menunjukkan bahwa dirinya adalah persekutuan yang bersifat kharismatis dan organis, bukan institusi atau organisasi. Ide tentang gerja sebagai satu organisasi lebih mengemuka terutama di Barat. ${ }^{4}$

Kesatuan dari kepelbagaian anggota gereja yang didasari pada transformasi yang dikerjakan oleh Roh Kudus dalam diri orang yang percaya, yang diikat oleh kasih adalah lebih kuat dari pada ikatan organisasi atau lembaga. Namun demikian pelembagaan gereja dalam berbagai denominasi bukanlah merupakan sesuatu yang salah. Gereja haruslah diatur sedemikian rupa, namun dengan tidak mengabaikan hal yang paling esensial. Gereja yang begitu menekankan peranan organisasi dengan semua peraturannya yang kaku, gereja tersebut adalah mati secara rohani. Peranan organisasi adalah faktor sekunder, yang terutama, gereja adalah persekutuan yang kharismatis dan organis.

Tatkala gereja lebih memberi penekanan pada organisasi dengan peraturan yang kaku dan kehilangan fungsi kharismatis dan organis, maka gereja tersebut akan gampang menghadapi bahaya perpecahan. Apabila gereja menyadari dirinya sebagai tubuh Kristus maka perpecahan merupakan sesuatu yang sangat absurd.

\section{Kepelbagaian Dalam Kesatuan Menurut Kisah Para Rasul}

Kisah Para Rasul diawali dengan pernyataan Tuhan Yesus: "Tetapi kamu akan menerima kuas, kalau Roh Kudus turun ke atas kamu, dan kamu akan menjadi saksiku di Yerusalem dan di Yudea dan Samaria dan sampai keujung bumi” Kisah 1:8. Ayat ini memberi isarat awal kepada murid-murid bahwa kelak jemaat Tuhan bukanlah hanya bangsa Yahudi saja (Homogen), tetapi juga mencakup segala bangsa, yaitu sampai keujung bumu (Hetrogen). Dengan demikian para Rasul dan jemaat mula-mula seharusnya sejak dari awal bersifat terbuka, siap untuk menerima kehadiran siapapun dan tidak bersifat eksklusif. Bahkan lebih dari sekedar terbuka mereka mentaati Amanat agung Penginjilan, pergi kepada bangsa-bangsa lain, agar bangsa-bangsa lainpun percaya dan menerima Tuhan Yesus sebagaimana yang mereka alami. Namun kenyataannya bersifat terbuka dan mentaati Amanat Agung Penginjilan bukanlah sesuatu yang gampang. Dalam Kisah Para

\footnotetext{
${ }^{4}$ Howard A. Snyder, The Community of the King, (Illinois: Inter Varsity Press, 1984) 58
} 
Rasul 8 menjelaskan betapa sulitnya gereja di Yerusalem untuk percaya bahwa di Samariapun orang mulai percaya. Latar belakang Yahudi, gereja mula-mula sangat kuat. Mereka tidak berlaku ramah terhadap orang Samaria (Yoh 4:9). Meskipun Tuhan Yesus telah memebri contoh bagaimana ia melayani perempuan Samaria dan orang-orang Samaria yang lain (Yoh 4). Tetapi juga Tuhan Yesus telah memberi perintah bahwa mereka akan menjadi saksi di Samaria (Kisah 1:8), semuanya memberi indikasi bahwa orang Samaria adalah sasaran perkhabaran injil dan mereka adalah kandidat orang percaya dan $\mathrm{k}$ arena itu gereja mula-mula harus taat dan terbuka.

Dalam Kisah Para Rasul 10 Tuhan memberi satu penglihatan kepada Petrus: Tampak olehnya langit terbuka dan turunlah suatu benda berbentuk kain lebar yang bergantung pada keempat sudutnya, yang diturunkan ke tanah. Di dalamnya terdapat berbagai jenis binatang berkaki empat, binatang menjalar dan burung. Kemudian terdengarlah suatu suara yang berkata: "Bangunlah hai Petrus, sembelihlah dan makanlah. Tetapi Petrus menjawab: “Tidak, Tuhan, tidak, sebab aku belum pernah memakan sesuatu yang haram dan yang tidak tahir. Kedengaran pula untuk kedua kalinya suara yang berkata kepadanya: "Apa yang dinyatakan halal oleh Allah, tidak boleh engkau nyatakan haram Hal ini terjadi sampai tiga kali. Penglihatan inilah yang membawa Petrus untuk pergi memberitakan Injil kepada Kornelius seorang Non Yahudi, bangsa yang tidak bersunat. Melalui penglihatan ini Petus menyadari bahwa ia tidak boleh lagi menyebut orang non Yahudi tidak tahir atau najis. Mereka juga menjadi sasaran perkhabaran Injil. Mereka juga butuh keselamatan. Pengalaman melayani keluarga Kornelius, pada waktu Petrus menceritakan tentang Tuhan Yesus, pada waktu itu turunlah Roh Kudus ke atas orang-orang yang percaya sama seperti kepada Petrus dan murid-murid pada hari Pentakosta. Dengan demikian Tuhan tidak mengadakan pembedaan antara orang percaya yang berlatar belakang Yahudi dan orang percaya yang berlatar belakang non Yahudi. Semua orang yang percaya kepada Tuhan Yesus menerima Roh Kudus.

Pemberitaan Injil kepada orang yang tak bersunat merupakan suatu konsep baru bagi orang Kristen Yahudi. Roh Kuduslah yang terus bekerja sehingga Injil terus diberitakan dan diterima mulai dari orang Yahudi tulen sampai kepada orang Yunani helenistik. Ketaatan orang Kristen Yahudi untuk keluar dari tradisi, merupakan satu ujian bagi universalitas injil. Hal ini sebagaimana diungkapkan oleh Hopler: 
Penyebaran Injil telah bergerak dari orang Yahudi Palestina yang tulen kepada orang Yunani Helenistik terus kepada orang Samaria dan kepada Sida-sida Etiopia, semuanya atas pengaruh yang kuat dari Roh Kudus. Semuanya ini melawan tradisi, ujian bagi universalitas injil adalah kesediaan Kristen Yahudi Palestina untuk pergi kepada orang kafir..$^{5}$

Gereja Antiokhia dalam Kisah 11 dan 13 adalah gereja pertama yang memiliki kepelbagaian background anggota. Ada orang Yahudi, ada orang Siprus, ada orang Kirene dan orang-orang Yunani.Benih awal gereja di Antiokhia adalah penganiayaan di Yerusalem. Karena penganiayaan ini banyak orang Kristen Yahudi Helenistik tersebar keluar dari Yerusalem. Di Antiokhia mereka memberitakan Injil kepada orang Yahudi Helenistik saja. Hal ini dapat dipahami, kebanyakan orang lebih merasa cocok untuk berkumpul dan memberitakan injil kepada orang ang berkebudayaan sama. Thom Hopler menceritakan pengalamannya pada waktu ke Afrika: "Ketika saya pergi ke Afrika, saya mendapati kecendrungan yang sama dalam diri saya. Adalah lebih gampang bagi saya untuk tinggal dan bersekutu dengan para missionaries dari Amerika yang ada di sana". 6 Demikian juga orang Kristen yang berlatar belakang non Yahudi mereka juga memberitakan Injil kepada orang non Yahudi. Di antara mereka ada pula orang Siprus dan orang Kirene yang tiba di Antiokhia, mereka memberitakan injil kepada orang-orang Yunani bahwa Yesus adalah Tuhan. Tangan Tuhan menyertai mereka dan sejumlah besar orang menjadi percaya dan berbalik kepada Tuhan.(Kisah 11:20-21). Dengan demikian jemaat di Antiokhia memiliki berbagai macam latar belkang bangsa dan budaya.

Perbedaan latar belakang bangsa dan budaya, seringkali menimbulkan konflik. Potensi rawan konflik itu sedapat mungkin harus diantisipasi. Agar konflik tidak menimbulkan perpecahan, maka jemaat di Yerusalem, setelah mendengar sejumlah besar orang Yahudi dan orang non Yahudi di Antiokhia berbalik kepada Tuhan, mereka memutuskan untuk mengirim Barnabas. Mengapa Barnabas?. Barnabas memiliki dua kebudayaan. Berbicara dalam bahasa Ibrani dan mengerti bahasa dan kebudayaan Yunani Helenestik. Itulah sebabnya jemaat Yerusalem menganggap Barnabaslah yang cocok untuk mempersatukan kedua kelompok orang percaya di Antiokhia.

Dikemudian hari Barnabas membutuhkan bantuan. Ia tidak kembali ke Yerusalem, melainkan ia pergi ke Tarsus untuk mencari Paulus, seorang yang juga memiliki kebudayaan ganda. Paulus, seorang warga Negara Roma tetapi juga ia adalah

\footnotetext{
${ }^{5}$ Thom Hopler, A World of Difference, (Illinois:Intervarsity Press, 1978) 101

${ }^{6}$ Thom Hopler, $A$ World..., 105
} 
seorang Farisi. Barnabas mengenal dengan baik latarbelakang dan pertobatan Paulus. Barnabaslah yang memperkenalkan Paulus kepada Rasul-Rasul setelah pertobatannya. Satu prinsip yang penting di sini ialah tatkala ada potensi untuk perpecahan, jangan pusatkan perhatian pada pokok persoalan, melainkan cari seseorang yang dapat memberi solusi yang dapat mempersatukan bahkan membuat pelayanan semakin bertumbuh. Barnabas adalah orang yang dipakai oleh Tuhan sebagai alat bagi Paulus untuk memulai tugas kerasulannya.

Setelah Barnabas datang dan melihat kasih karunia Allah, bersukacitalah ia. Ia menasihati mereka agar mereka tetap setia kepada Tuhan (Kis. 11:23). Kristus adalah pusat berita seorang Counsellor, sebab Kristuslah yang merupakan dasar sebuah gereja. Barnabas tidak memberitakan tentang sunat atau tentang pemakaian bahasa, melainkan ia memusatkan perhatian kedua belah pihak kepada Kristus. Di sinilah pusat kebersamaan diletakkan. Sebagai akibatnya adalah: Pertama, Di Antiokhialah untuk pertama kali muridmurid di sebut Kristen (Kis. 11:26). Kedua, Tatkala diberitakan akan terjadi bala kelaparan yang hebat, jemaat di Antiokhia memutuskan untuk memberikan sumbangan bagi jemaat di Yerusalem. Hal ini menunjukkan bahwa jemaat Antiokhia telah sanggup untuk menjadi satu dengan saudara-saudara yang lain dalam hal saling berbagi. Kesatuan bukan hanya di bibir saja. Ketiga, Paulus dan Barnabas mampu melahirkan pemimpin-pemimpin lokal yang handal (Kis.13:1). Keempat, Jemaat Antiokhia menjadi jemaat yang multi budaya. Jemaat yang multi budaya gampang terbuka terhadap budaya yang lain. Hal ini membuat mereka siap mentaati amanat agung yang menjadikan jemaat Antiokhia, jemaat yang missioner. Pada akhirnya oleh Roh Kudus jemaat Antiokhia mengutus Barnabas dan Paulus untuk menjadi pemberita Injil di tempat-tempat yang lain.

Kebersamaan Paulus dan Barnabas berakhir dengan terjadinya perselisihan yang tajam antara Paulus dan barnabas. Perselisihan ini berawal tatkala Paulus mengajak Barnabas untuk mengunjungi jemaat di kota-kota yang telah mereka injili. Barnabas ingin membawa Yohanes Markus, sedangkan Paulus menolak dengan keras, karena Yohanes Markus pernah meninggalkan Paulus dan Barnabas di Pamfilia dan tidak mau turut bekerjasama dengan mereka. Perselisihan ini menyebabkan Paulus berpisah dengan Barnabas. Barnabas pergi bersama dengan Yohanes Markus dan Paulus pergi dengan Silas (Kis. 15:35-41). 
Perpecahan Paulus dan barnabas ini, seringkali telah dijadikan bahan acuan bagi perpecahan gereja, tatapi apakah perpisahan Paulus dan Barnabas merupakan tindakan yang benar, sehingga dapat dijadikan acuan?. Meskipun perpecahan Paulus dan barnabas mempunyai nilai yang positif, sebagaimana diungkapkan oleh Everett F Harrison dalam the Expositor's Bible Commentary: "Meskipun ketidak sesuaian itu merusak penyebaran injil, namun Allah mentakdirkannya untuk melipatgandakan kekuatan missionary. ${ }^{7}$ Namun pertanyaannya adalah apakah pelipatgandaan misionaris harus melalui perpecahan? Sehingga dilihat dari sudut manapun juga, perpecahan tidak dapat diterima oleh akal yang sehat. Paulus dan barnabas adalah manusia biasa yang tidak luput dari kesalahan. Karena itu perpecahan Paulus dan Barnabas tidak dapat dijadikan alasan pembenaran terjadinya perpecahan gereja.

Barnabas, artinya adalah "anak penghiburan”. Tatkala jemaat-jemaat masih menyangsikan pertobatan Paulus, Barnabaslah yang memperkenalkan Paulus kepada Rasul-rasul. Tatkala Paulus berada di Tarsus dan belum dikenal orang, Barnabaslah yang mengajaknya untuk bergabung dengannya untuk melayani di Antiokhia. Sebagai "anak Penghiburan" pelayanannya adalah memberikan penghiburan, menguatkan, mengangkat hidup orang lain serta memberikan kesempatan agar orang lain mengalami kemajuan. Demikian pula tatkala Yohanes Markus mau bergabung kembali dalam pelayanan Paulus dan barnabas setelah meninggalkan mereka di Pamfilia, Paulus menolak dengan tegas, karena ia menganggap tidak baik membawa serta orang yang telah meninggalkan mereka di pamfilia dan tidak mau turut bekerja bersama-sama dengan mereka (Kis. 15:38). Atau dengan kata lain tidak baik membawa orang yang pernah berkhianat. Namun Barnabas ingin membawa Yohanes Markus kembali.

Mungkin ada yang mengatakan karena Yohanes Markus adalah keponakan Barnabas (Kolose 4:10) sehingga Barnabas mau menerimanya kembali. Tidak!. Barnabas bukanlah seorang yang nepotisme. Ia adalah anak penghiburan. Barnabas berorientasi pada manusia. Ia senantiasa memberikan kesempatan kedua (Second Chance) bagi seseorang untuk bangkit dari kegagalan. Paulus berorientasi pada tugas, pada misi. (Mission oriented).

${ }^{7}$ Everett F. Harrison, The expositor's Commentary, (Grand Rapids: Zondervan Publishing House, 1976) 454 
Barnabas berhasil membina Yohanes markus. Dikemudian hari Paulus pun menyadari kekeliruannya. Ia menulis surat kepada Timotius: "Jemputlah Markus dan bawalah kemari, karena pelayanannya penting bagiku" (2 Tim. 4:11). Selanjutnya dalam suratnya yang lain, Paulus mengatakan bahwa Yohanes Markus menjadi teman sekerja Paulus dan sangat memberi penghiburan kepada Paulus (Kolose 4:10-11, Filemon 1:24). Tadinya Paulus menganggap Yohanes markus seorang yang tidak berguna lagi, sebab ia seorang pengkhianat, tetapi kemudian Yohanes Markus membuktikan bahwa ia seorang yang berguna, seorang yang setia, seorang yang dapat dipercaya. Dengan demikian terdapat indikasi yang jelas sekali bahwa bukan hanya hubungan Paulus dan Yohanes Markus yang pulih kembali, tetapi juga hubungan Paulus dengan Barnabas, sebab dengan Paulus menerima kembali bahkan memuji kesetiaan Yohanes Markus, Paulus mengakui kebenaran pendirian Barnabas yang menyebabkan mereka tadinya berpisah. Paulus telah memulihkan kembali hubungan dengan Barnabas. Penerimaan Paulus terhadap Yohanes Markus merupakan pengakuan bahwa Barnabas adalah "anak penghiburan" (Kisah 4:36$37)$.

Dengan demikian perpecahan Paulus dan Barnabas tidak boleh hanya dilihat dari perikop Kisah Para Rasul 15:35-41 saja, sehingga memberi pembenaran terjadinya satu perpecahan. Meskipun perpecahan memiliki nilai positif tetapi harus disadari bahwa perpecahan sangat bersifat negatif baik dalam hubungan dengan koinonia, diakonia maupun marturia.

\section{Kepelbagaian Dalam Kesatuan Menurut Surat-Surat Paulus}

Pada bagian ini tidak akan dibahas lagi surat Paulus kepada jemaat di Korintus. Bagian ini hanya akan memperhatikan apa yang Paulus katakan tentang kepelbagaian dalam kesatuan dalam surat Roma, Efesus dan Kolose.

\section{Roma 12: 3-8}

Bagian ini paulus mulai dengan kalimat: "Berdasarkan kasih karunia yang dianugrahkan kepadaku..." Paulus belum pernah pergi ke Roma, sehingga ia tidak tahu karunia apa yang dimiliki oleh jemaat di Roma dan jemaat di Roma pun tidak tahu karunia apa yang dimiliki oleh rasul Paulus, tetapi berdasarkan kasih karunia yang Tuhan anugerahkan kepadanya, Paulus mengetahui bahwa setiap orang yang percaya diberi karunia Roh Kudus. Dengan demikian ayat 3 merupakan introduksi penggunaan karunia 
dalam ayat-ayat selanjutnya. Karena karunia-karunia ini dari Allah maka kita harus berfikir benar. Don D. Welt mengomentari ayat ini sebagai berikut:

Kita tidak boleh menjadi tinggi hati sebab kita dikaruniai, tetapi kita harus berfikir benar, bahwa kita harus menempatkan secara tepat segala sesuatu, secara khusus karunia-karunia. Karunia kita sama baiknya dengan karunia orang lain....jangan sombong dan jangan merendahkan orang lain, karena ia memiliki karunia yang kurang bersinar. ${ }^{8}$

Oleh karena karunia-karunia ini berasal dari Allah, maka kita harus berfikir benar. Terjemahan Baru memakai kalimat: "Janganlah kamu memikirkan hal-hal yang lebih tinggi dari pada yang patut kamu pikirkan". Namun Terjemahan Lama menggunakan kalimat: "Janganlah menyangka dirimu berlebih-lebih". Karena ada kecendrungan orang merasa penting dan menjadi congkak karena telah diberikan karunia tertentu, maka Paulus mengingatkan mereka agar mawas diri dan menghindari menganggap diri lebih penting dan menganggap orang lain lebih rendah.

Dalam ayat 4-5 ada dua hal penting yang perlu mendapat penekanan yang memiliki hubungan satu dengan yang lain. Pertama, "Tidak semua anggota itu mempunyai tugas yang sama" dan kedua, "Kita masing-masing adalah anggota yang seorang terhadap yang lain". Sebenarnya bukanlah untuk pertama kali Paulus pakai sebagai satu perbandingan dan bukan pula yang terakhir (Band 1 Kor 12:12-27). Bagian ini memberi penekanan pada "Kesatuan yang sempurna dari kepelbagaian dalam tubuh manusia". Kesimpulan yang tersembunyi di dalamnya adalah: "Kesatuan respons terhadap satu kepala”. Di dalam tubuh rohani, yaitu gereja, Kristus adalah Kepala (Efesus 1:22-23). Adalah satu keinginan yang sempurna dari tiap-tiap anggota untuk menganggap yang lain lebih baik dari pada dirinya sendiri dan sama-sama penting sebagaimana dirnya sendiri. Tidak ada pengecualian bahwa semua bagian mengerjakan apa yang anggota lain tidak dapat kerjakan, karena itu betapa penting adanya kerjasama tiap-tiap anggota dalam keterikatan hubungan dengan satu kepala, sebgaimana diungkapkan oleh Don D Welt: "Ketika kita menyadari bahwa hubungan yang tepat pada kepala bergantung pada hubungan yang tepat pada setiap anggota tubuh yang lain, kita akan bekerjasama tanpa merasa tinggi hati". 9

Dengan demikian jelaslah bahwa yang Paulus maksudkan adalah hubungan dengan Kristus sebagai Kepala Gereja membawa dampak pada persekutuan Kristen

\footnotetext{
${ }^{8}$ Don D Welt, Roman Realized, (Joplin Missoury: College Press, 1967) 198

${ }^{9}$ Don D Welt, Roman Realized..., 200
} 
sebagai kesatuan social dimana anggota-anggota yang berbeda itu bekerja sama dan saling melayani. ${ }^{10}$ Selanjutnya dalam ayat 6-8 Paulus menyebutkan beberapa karunia yang harus digunakan sebagaimana telah diuraikan di atas:

\section{$\underline{\text { Karunia Bernubuat }}$}

Paulus katakan: Jika karunia itu untuk bernubuat, baiklah kita melakukannya sesuai dengan iman kita (6). Hal itu berarti bahwa seseorang yang dikaruniakan karunia ini harus berbicara sesuai dengan apa yang diberikan oleh Allah, tidak boleh dilebihkan dan tidak boleh dikurangi. Ia tidak boleh berbicara dalam emosi (1 Kor 14:32) atau dalam kecintaannya untuk berbicara (1 Kor 14:30), melainkan dengan bergantung seluruhnya pada Roh Allah.

\section{$\underline{\text { Karunia Melayani }}$}

Kata ini diterjemahkan dari kata diakonia, yang menujuk kepada pelayanan jasmani kepada mereka yang membutuhkan. Pelayanan ini merupakan bentuk kepedulian nyata kepada semua orang terutama kepada orang percaya Galatia 6:10 dan merupakan wujud nyata iman kepada Tuhan. Karena iman tanpa perbuatan adalah mati. Yakobus 2:16-17)

\section{$\underline{\text { Karunia Mengajar }}$}

Menurut Harrison, karunia ini lebih bertujuan menolong pada area kehidupan Kristen dari pada mengajarkan tentang doktrin. ${ }^{11}$ Karunia ini seringkali disejajarkan dengan karunia sebagai gembala dan pemberita injil. Efesus 4:11

\section{$\underline{\text { Karunia Menasihati }}$}

Berasal dari kata paraklesis yang berarti, encouragement, exhortation, confort (memberi dorongan atau semangat, desakan atau memberi peringatan, menghibur). Yusuf disebut oleh Rasul-Rasul dengan nama Barnabas, artinya anak penghiburan dan sepanjang hidupnya ia membuktikan diri sebagai anak penghiburan.Kisah 4:36-37 murah hati, contributing to the needs of others. Memberi dengan bersifat spontanitas.

\section{Karunia Membagi-bagi Sesuatu}

Karunia ini adalah karunia memberi. Semua orang Kristen harus bisa memberi khususnya memberi persembahan seperti dikatakan oleh firman Tuhan, tetapi orang yang

\footnotetext{
${ }^{10}$ Donald Guthtrie, Tafsiran Alkitab Masa Kini, (Jakarta: OMF, 1985) 473

${ }^{11}$ Everett F Harrison, The Expositor's...., 131
} 
diberi karunia untuk membagi sesuatu memiliki kekhususan. Ia memberi dengan tidak dengan perhitungan untung rugi.

\section{$\underline{\text { Karunia Memimpin }}$}

Siapa yang memimpin hendaklah ia melakukannya dengan rajin. Dan penuh dengan kepedulian. Seorang pemimpin adalah seorang yang dikarunia kemampuan sehingga ia diikuti oleh orang lain. Pemimpin Kristen senantiasa menjadi contoh dan membuat orang lain berorientasi kepada Kristus.

\section{Karunia Menujukkan Kemurahan}

Hal ini lebih ditujukan kepada perhatian terhadap orang sakit atau orang miskin dan Paulus katakan hendaklah melakukannya dengan sukacita. If you come with simphaty to sorrow, bring God's sunlight in your face. Sebagaimana uraian Paulus tentang kepelbagaian dalam kesatuan dalam 1Korintus 12 dilanjutkan (Tidak terpisahkan dari) dengan perikop tentang kasih dalam 1 Kor. 13 demikian pula dalam Roma 12 3-8 dilanjutkan dengan perikop berikutnya dengan judul yang sama: "Kasih". Hal ini untuk menunjukkan bahwa semua karunia-karunia itu, hanya mungkin bekerja dengan efektif manakala dilakukan dalam kasih.

\section{Efesus 2:11-22}

Pada bagian ini Paulus menyatakan bahwa gereja adalah satu umat yang baru. Umat yang telah dipersatukan oleh Kristus. Latar belakang umat yang baru tersebut adalah bangsa Yahudi dan non Yahudi. Paulus menyebut bangsa Yahudi sebagai "Mereka yang dekat", sedangkan bangsa non Yahudi Paulus sebut: "Kamu yang dahulu jauh". Mereka disebut jauh oleh karena:

1. Kamu dahulu tanpa atau terpisah (separate) dari Kristus. Kamu dahulu tanpa pengharapan akan Mesias yang akan menyinari kegelapanmu

2. Kamu dahulu tidak mempunyai hak sebagai warga (Politeia) dalam kerajaanNya. Kamu tidak memiliki hak istimewa itu oleh karena factor kelahiran (Faktor keturunan)

3. Kamu hidup tanpa Allah. Dengan demikian hidup terasing tanpa hak prerogative. Hidup di dunia tanpa pengharapan. Hal ini tidak berarti bahwa mereka diabaikan oleh Allah, tetapi lebih berarti bahwa mereka tidak mengenal Allah. (Gal 4:8). Mereka tidak percaya kepadaNya. 
Setelah mengungkapkan keadaan orang Kristen Efesus dahulu, Paulus melanjutkan dengan ayat 13: Tetapi sekarang di dalam Kristus, kamu yang dahulu jauh, sudah menjadi dekat. Oleh darah Kristus. Karena Dialah damai sejahtera kita yang telah mempersatukan kedua belah pihak dan yang telah merobohkan tembok pemisah, yaitu perseteruan, sebab dengan matinya sebagai manusia, Ia telah membatalkan hukum taurat dengan segala perintah dan ketentuannya, untuk menciptakan keduanya menjadi satu manusia baru di dalam diriNya dan dengan itu mengadakan damai sejahtera. Dan untuk memperdamaikan keduanya, di dalam satu tubuh dengan Allah oleh salib, dengan melenyapkan perseteruan pada salib itu. (13-16). Ada beberapa hal yang perlu mendapat penekanan pada ayat-ayat tersebut:

1. Allah telah meniadakan (Menghapuskan )aspek dari hukum taurat yang telah membuat bangsa Israel menjadi bangsa yang terpisah/istimewah.

2. Di dalam Yesus Kristus, kamu yang dahulu "jauh" sudah menjadi dekat. Oleh darah Kristus.

3. Tembok pemisah yaitu perseteruan telah dirobohkan. Keduanya telah diperdamaikan.

4. Kristus mengadakan damai sejahtera.

5. Sebagai hasilnya ialah: Keduanya menjadi manusia baru dalam diriNya, serta menjadi satu tubuh.

Manusia baru ini, yakni gereja merupakan satu perkumpulan yang mengagumkan dan meliputi banyak hal. Kristus telah meniadakan lebih dari sekedar penghalang-penghalang kesukuan dan kebangsaan. Dia telah menghapus penghalang kelas dan gender: Tidak ada orang Yahudi dan orang Yunani, tidak ada hamba atau orang merdeka, tidak ada laki-laki atau perempuan, karena kamu semua adalah satu di dalam Kristus. (Gal 3:28). Di dalam Kristus tidak ada lagi diskriminasi. Setiap orang sama berharganya di dalam Kristus.

Sebagai akibatnya adalah semua orang yang percaya pada Kristus adalah kawan sewarga dari orang-orang Kudus dan anggota keluarga Allah. Menjadi ahli waris dan anggota-anggota tubuh dan peserta dalam janji yang diberikan dalam Kristus karena berita Injil 3:16). Sehubungan dengan ini John Stott Mengungkapkan:

Di dalam ayat-ayat ini Paulus memakai empat kata majemuk dari bahasa Yunani. Yang kemudian diterjemahkan menjadi "Kawan sewarga" (Fellow citizen), "Ahli-ahli waris" Fellow Heirs), "anggota-anggota" (Fellow members), dan "peserta" (fellow Partakers) untuk menegaskan sejelas dan 
sekuat mungkin mengenai partisipasi umum dan tidak boleh dibedakan dari seluruh umat Allah dalam seluruh berkat yang terdapat di dalam injil. ${ }^{12}$

Dengan demikian karya Kristus di atas kayu salib menciptakan kesatuan dan kesetaraan di hadapan Allah. Karena itu tidak ada satupun anggota tubuh -dengan karunia apapun yang Allah berikan kepadanya- merasa superior atau imferior. Pemberian karunia oleh Allah kepada anggota tubuh tidak untuk meningkatkan status. Setiap anggota yang diberikan karunia, karunia apapun, harus tetap memiliki hati sebagai hamba. Hati seorang pelayan. Penuh dengan kerendahan hati. Merasa superior atau imferior adalah tembok pemisah yang merupakan benih awal dari satu perpecahan dan dengan demikian harus dirobohkan. Persatuan yang Paulus maksud lebih menunjuk kepada personal unity. Perseteruan, merasa superior atau imferior adalah rintangan yang menghalangi terjadinya personak unity tersebut. Perpecahan satu gereja seringkali diawali oleh retaknya hubungan pribadi.

\section{Kolose 3:10-11}

Di dalam ayat 10 Paulus memberikan alasan mengapa kita tidak boleh mendustai orang lain: Kita telah mengenakan manusia baru. Manusia baru tersebut: 1 . mematikan segala sesuatu yang duniawi dan segala sifat dan tabiat manusia lama. 2. Terus menerus diperbaharui dan bertumbuh sehingga menjadi serupa dengan gambar AnakNya. 3. Di dalam manusia baru tidak ada perbedaan ras dan status social karena Kristus adalah semua dan di dalam segala sesuatu.

Di dalam ayat 11 Paulus mengatakan: "Dalam hal ini tiada lagi orang Yunani atau orang Skit, budak atau orang merdeka, tetapi Kristus adalah semua dan di dalam segala sesuatu". Yunani-Yahudi, Bangsa Yunani terlibat dalam peperangan yang amat pahit dengan bangsa Yahudi pada tahun165 BC, yaitu pada masa Makkabe. Namun penempatan pasangan Yunani dan Yahudi bukanlah karena akar pahit pada masa lampau. Tetapi lebih kepada dua kutub sudut pandang yang berbeda. Bangsa Yunani lebih mementingkan hikmat dan fisafat, sedangkan bangsa Yahudi lebih mementingkan kesalehan. Bangsa Yunani memandang bangsa Yahudi tidak berbudaya, tidak terpelajar dan bangsa Yahudi memandang bangsa Yunani sebagai bangsa kafir.

Bersunat-tak bersunat. Hal ini menunjukkan adanya perbedaan antara bangsa Yahudi dan non Yahudi. Bangsa Yahudi bangsa yang bersunat dan bangsa lain tidak

\footnotetext{
${ }^{12}$ John Stott, Satu Umat, (Malang:Seminari Alkitab Asia Tenggara) 13
} 
bersunat. Bangsa Yahudi sebagai umat Allah dan bangsa lain bukan umat Allah. Selama berabad-abad orang-orang non Yahudi dihinggapi oleh perasaan atas prasangka sikap anti Semit. Demikian juga bangsa Yahudi dihinggapi rasa bersalah atas prasangka sikap anti goyim (anti Gentile). Bangsa Bar-bar. Istilah ini ditujukan oleh orang-orang Yunani terhadap orang-orang yang bodoh bahasa mereka (Bahasa Yunani), sebagaimana jika seseorang berbicaraseperti bayi yang baru belajar mengucapkan suku kata bar - bar. Bangsa Skit. Orang Skit berasal dari sebelah selatan Rusia. Mereka pernah menginvasi Timur Tengah dan Palestina pada lebih kurang tahun 625 BC. Mereka dipandang lebih tidak beradap dari pada Bar-bar. Budak -Merdeka. Kristus adalah Tuan di atas segala tuan dan saudara bagi para budak. Dengan demikian karena Kristus menerima para budak sebagai saudaraNya, maka para budak adalah saudara bagi semua orang yang percaya.

Aplikasi terhadap apa yang Paulus tulis kepada jemaat Kolose adalah surat Paulus kepada Filemon. Filemon adalah seorang Penatua, seorang yang kaya dan terpandang di jemaat Kolose. Dalam surat kepada Filemon, Paulus meminta kepada Filemon untuk menerima kembali Onesimus, bukan lagi sebagai hamba, melainkan sebagai saudara yang kekasih. Onesimus adalah hamba keluarga Filemon. Oleh karena ada suatu kesalahan akhirnya ia masuk penjara. Di penjara ia bertemu dengan Paulus. Ia dilayani oleh Paulus dan menerima Tuhan Yesus. Ia diperbaharui oleh Tuhan. Oleh karena sudah percaya dan mengalami pembaharuan, Paulus ingin supaya Filemon, sebagai seorang penatua yang sudah diperbaharui oleh Tuhan, membuktikan bahwa seorang hamba yang sudah di dalam Tuhan adalah saudara sesama anggota tubuh Kristus. Di dalam Tuhan tidak boleh lagi merasa bahwa ia lebih terhormat dari pada Onesimus. Berdasarkan surat Paulus ini Filemon menerima kembali Onesimus bukan lagi sebagai hamba tetapi sebagai saudara yang kekasih. Bahkan ada legenda -yang belum tentu kebenarannya- mengatakan bahwa dikemudian hari Onesimus menjadi Bishof di Efesus. ${ }^{13}$ Dengan demikian surat Paulus kepada Filemon, meskipun sangat singkat dan nampak seperti tidak berarti, tetapi ia bagaikan bintang terang di tengah malam yang gelap. Mengapa? Para Filsuf sperti Aristoteles memandang para budak bukan sebagai manusia melainkan sebagai hak milik/kekayaan. The Philosophers such as Aristotle, di not regard slaves as human being, but as property as extensions of the master's body. ${ }^{14}$ Di Kekaisaran Romawi ada jauh lebih banyak budak dari pada orang Merdeka. Di kota Korintus saja ada 400,000; budak dan

\footnotetext{
${ }^{13}$ Wilbur Fields, Bible Studies Textbook Series: Philipians, Collosians, Philimon, (Joplin Missoury: College Press, 1984), 256

${ }^{14} \mathrm{Ibid}, \ldots, 256$
} 
hanya 250,000; orang merdeka. Demikian juga di Kota Atena, ada lebih banyak budak di bandingkan orang Merdeka. Budak-budak ini biasanya didapatkan pada waktu peperangan. Orang kaya Roma kadang-kadang bisa memiliki 10 sampai 20 ribu budak. ${ }^{15}$

Di dalam Perjanjian Lama para budak tidak lebih dari barang dagangan (Imamat 25:24). Demikian pula dalam sejarah dunia ini diskriminasi dan perbudakan telah terjadi bahkan di Negara yang mayoritas beragama Kristen, seperti di Amerika. Demikian pula dengan politik Apartheit di Afrika Selatan. Karena itu Kekristenan yang benar adalah satu revolusi kasih, yang menunggangbalikkan tatanan masyarakat yang sudah mapan dan sangat diskriminatif. Di dalam Kristus latar belakang menjadi tidak penting lagi. Bangsa Bar-bar, bangsa Skit, para budak, tidak perlu merasa inferior atau minder lagi. Untuk menjadi satu dengan bangsa Yahudi maupun bangsa Yunani. Demikian juga bangsa Yahudi dan bangsa Yunani harus melepaskan kebanggaan mereka selama ini untuk mnejadi satu dengan bangsa Bar-bar, Skit bahkan para budak. Sebab bukankah Tuhan Yesus, yang walaupun dalam rupa Allah, tidak menganggap kesetaraan dengan Allah itu sebagai milik yang harus dipertahankan, melainkan telah mengoosongkan diriNya, dan mengambil rupa seorang hamba dan menjadi sama dengan manusia (Fil 2:6-7). Kristus telah menjadi teladan bagaimana bersikap terhadap sesama. Tidak ada yang terlalu tinggi dan tidak ada pula yang terlalu rendah untuk dijadikan sesama..

\section{RANGKUMAN}

Kepelbagaian jemaat dengan kepelbagaian karunia, kepelbagaian etnis, kepelbagaian status social bersumber dari Allah Tritnggal. Pada waktu Tuhan Yesus melayani Ia memilih murid-murid dari berbagai latar belakang: Nelayan, pemungut cukai, dll serta memiliki berbagai macam temperamen. Amanat Penginjilan kepada segala Bangsa Mat 28:19-20, Kisah 1:8 adalah amanat bagi pencapaian keselamatan bagi banyak bangsa dan kelak di Sorga akan berdiri di hadapan Anak Domba Allah orang-orang dari segala bangsa. Wahyu 7:9. Hak istimewa Bangsa Israel sebagai umat Allah dihapuskan, tembok pemisah itu telah dirobohkan oleh salib Kristus, sehingga tercipta satu umat yang baru, yaitu gereja. Pertikaian yang telah terjadi sejak zaman Rasul Paulus dan Barnabas demikian juga antara Filemon dan Onesimus mengalami pemuliahan.

\footnotetext{
${ }^{15}$ Ibid, .., 256
} 


\section{DAFTAR PUSTAKA}

A. Snyder, Howard, 1984 The Community of the King, Illinois: Inter Varsity Press

Collins, Michael dan Matthew A. Price, 2006 The Story Of Christianity, Penerbit: Kanisius

D Welt, Don

1976 Roman Realized, Joplin Missoury: College Press

Fields, Wilbur,

1984 Bible Studies Textbook Series: Philipians, Collosians, Philimon, Joplin Missoury: College Press

F. Harrison, Everret,

1976 The expositor's Commentary,

Grand Rapids: Zondervan Publishing House

Guthtrie, Donald,

1985 Tafsiran Alkitab Masa Kini, Jakarta: OMF

Hopler, Thom,

1978 A World of Difference, Illinois:Intervarsity Press

Stott, John,

Satu Umat, Malang:Seminari Alkitab Asia Tenggara 